\title{
Thought experiments in construction risk management: capacities and limits
}

\author{
Taras Varkhotov" and Kira Alasania \\ Lomonosov Moscow State University, Faculty of Philosophy, Department of philosophy and \\ methodology of science, 119991, Moscow, GSP-1, Lomonosovsky prospekt, 27-4, Russia
}

\begin{abstract}
The article considers the concept of the thought experiment in risk management and describes epistemic status of the "risk" notion as well as conditions for performing procedures that contribute to risk management in construction. The article shows the prognostic and evidential potentials of the thought experiment as the basics for estimating the tools for risk analysis. The article states that the concept of risk management referring more to the plan of representation, than to the plan of reality let us include the thought experiment into the range of tools of risk estimations. Basing on the examples of construction activities as a specific sphere of risk management, the article proves the need of usage the thought experiment in applied forecast disciplines such as risk management.
\end{abstract}

\section{Introduction}

The theme of risk is one of the key ones for social sciences to the degree they claim for practical value and connection with actual reality. We use the term "theme" in the meaning given by G. Holton: an epistemic invariant existing at the level of intuition (Holton himself ranks them among scientific imagination peculiarities of a certain researcher [1,3-25]). The themes open a prospect for the subject and act as heuristics suggesting acceptable and nonacceptable decision trajectories.

From this point of view, "risks" as well as "risk estimations" and "risk management" generated by the same theme belong more to the plan of representation than to the plan of reality and they are tightly connected to another theme that is extremely popular in modern social science - ambiguity (ref. [2]). Risks appear as an effect of the fundamental ambiguity of the future and its partial dependence from our actions. Such representation of reality (historically, not nearly the only one) lets us consider "risk" as something "real" (measurable, for instance) and suggest strategies for working with risks dealing with them as with something actually real, almost material. In fact, risk management is an example of a strategy of this kind.

Meanwhile, the discussions about what could be called risk ontology, - the attempts to answer the question what is it, - make us doubt the ontological status of this subject. As

\footnotetext{
Corresponding author: varkhotov@gmail.com
} 
one of the most sophisticated and influential researchers of the social sphere N. Luhmann notes, "there is no such a notion of risk that could correspond to scientific claims. /.../ ...Even at the level of separate subject areas and even more in mutual inter-disciplinary working, there could be doubts if it is known what we are talking about"; at the same time, "the external world itself does not know any risk, because it is not aware of distinctions, expectations, estimations, probabilities" [3, 14-15].

Thematic connection of risk and ambiguity pushes us to define risk in the link with possibilities: risks are a particular measurement of possibilities apprehended as the potential future taken in the modality of our worry about our possibilities. Risks are a negative projection of a model of the required future, in other words, this is something that is included as an undesired possibility into a set of positive expectations connected to one or another strategy of our actions (positive possibility). (ref. [3, 19-20]). Accordingly, thematisation of risks, perhaps, derives from the quantum growth of possibilities (cf. with the concept of "risk society" [4]) making us pay the attention to the fly that potentially exists in the ointment: the size of the fly turned out to be too big to ignore this it when planning.

So, it is fair to say that "risk" is a way of thematisation of the future in constructing a forecast and, accordingly, planning activities in the cases, when 1) we speak about the future closely connected to our possibilities; 2) our possibilities are great enough to expect serious changes in the future depending on how we will use them.

The risk interpreted this way immediately points out essential irremoveability of the social context when discussing "risks" (because they derive from capabilities, plans and values of a person and not from material reality) and poses the question: how far and on what grounds we can consider our "risk management" tools to be valid and really capable for fulfilling the function they have. The question is formulated as following: to what extent our tools connected to the risk theme are objective? In other words, is it real and is it true that we manage something when we "work with risks" and what exactly we measure/estimate/correct?

In the following, we will try to answer this question defining the status of specific procedures (of "risk management"), taking into consideration the epistemic status of risk described above as well as the analysis of conditions for implementing the procedures that help to work with risks.

\section{Methods}

Working with risks - whatever we imagine when speaking about this procedure - always assumes that we deal with the future. Risks appear in connection with forecasts and always belong to the sphere of potential, which is possible but not real. Ultimately, any discussions about the future have this status, because the future is defined as something that does not exist. However, at the basis of any rational forecasting, the intuition of, at least, partial predeterminacy of the future assigned by the present, is. Otherwise, forecasting would be predicting activity in the sense of clairvoyance without any evidence base and somehow satisfactory arguments.

So, the reason for distrust in any forecast is simple and obvious: the forecast subject does not exist in a strict sense, because future, by definition, is not the reality - it plainly does not exist. From this point of view, any estimation of risks can be interpreted as a tool for artificial escalation of costs by means of including charges of hypothetic losses into the project budget. This kind of losses are not obligatory but could be unlike expenses that are really included. What are the rational grounds for trust in the forecasts? Making no claims for an exhaustive reply, we can mark at least two grounds of this kind. 
The first ground is that reality consists of the flow of linked events and these events are partly determined by causes producing them. In other words, causes or, we can say, fundamentals (archē or principia) of the future can exist in the present; a part of an event that mostly belongs to the future can exist in the observed present. This ground assuming a possibility to reveal a part of essential causes of the event that is not started in the present can be called ontological. It proceeds from continuity and causality of the reality (from the absence of fundamental ruptures and causeless events - as detailed ref. [5]).

The second ground is connected with social and constructive nature of the future - with something that does not just "happen" but that is created by the human and belongs to the field of their technological capacities being a result of purposeful material and technical activities or their lateral discharge. The notion of risk is exactly connected with this last script. The majority of risk management models, regardless a particular sphere, proceed from the intuition of risk management implemented by means of regulating possibilities at the stage of target and tool setting - constructing a model of the required future that, having constructive character, inevitably should include not just an image of the future but representation of tools and procedures capable of producing this future (ref., for ex., [6-7]). This particular choice of the "constructive way" for the "required future" is a zone for analyzing "side negative possibilities" included into a set of "needed preferable possibilities". This ground can be called constructive.

So, risk estimations as a part of forecasting is primary based on the constructive foundation - on the confidence in the future considerably being a projection of our targets and tools. And these targets and tools can contain important unrequired side components.

\section{Results and discussion}

Historically, risk management is tightly connected to the problem of responsibility (including legal one) for external effects of different kinds - unintended negative results of engineering and technical activities. One of the oldest precedents of this sort is the Rylands v. Fletcher tort (1866), whose results let the judge of the Appeal court Blackburn formulate a principle that after became a classic principle of responsibility. The just principle of law is the principle, according to which, a person bringing something to its land, collecting and storing something that can potentially do harm in the case of its leaking must, at their risk, prevent leaking. If the person does not do that, then they are presumed responsible for all the damage caused by leaking. The one who brings something that was not there before and stays safe till kept inside one's own domain to its land but, as one knows, it becomes harmful if it gets to the neighbor's domain, they must compensate the harm that will be done, if it is impossible to prevent the substance from moving beyond the limits of one's land. [8].

The decision on the Rylands v. Fletcher tort reflects a basic change in correlation of ontological and constructive components of the forecast: allocation of strict responsibility for side unintended consequences of construction activities (Fletcher built a reservoir and accidently flooded Rylands' mine by water that came to the mine by a shaft that was not known to Fletcher at all) proves that engineering and technical capabilities grown to the extent that all the results produced by them including accidental ones have the scale that does not let us consider even some of them insignificant.

The problem of responsibility in risk management acquires additional meanings when it moves to the sphere of risk insurance. And, in this sense, the example of insuring constructing and assembling risks is of the specific interest because of two reasons. The first reason is connected with the complexity of constructing and assembling risks in comparison to other technical risks, the second one is linked to communicative aspects we cannot avoid when speaking about the sphere of insuring such kind of risks. 
Considering the first reason, it is important to mention the following: despite the fact that the frequency of insurance events in construction is less than in other spheres (vehicle insurance, for instance), the amount of loss and damage in construction is more, because construction risks include both vulnerability factors of the project decision and vulnerability factors of the object construction system. Clarifying the second reason, it is to be noted that insuring technical risks compared to some other types of insurance often presumes international cooperation, because construction of a significant object demands participation of various contractors and suppliers of different countries. Each one prefers to be insured in their states, which is natural for modern international practice. However, the situation is different in Russia. A lot of Russian contractors prefer to get their insurance from foreign agents, which is determined by inner problems of the insurance market (insufficient financial stability of Russian insurance companies, insufficiency of insurance coverage etc.) This situation leads to negative situations that makes risk management ineffective. One of the examples is the case of the flood at the PSP in Zagorsk, when one of the biggest Russian insurance companies failed in communication with the German one in terms of risks' insurance. The most challenging point was in the question of misunderstanding of risk insurance contract terms. The main claim of the German insurer was that Russian company represented the risks as separate ones but, in fact, they should be presented as the cumulative risk. Contradicting the opponent, the representative of the Russian company claimed that insurance business is mainly built upon conceptual but not legal basics. A range of conditions are just discussed but not necessarily documented [9].

This paradox example illustrates that some risks cannot be measured just because the causes of these risks are hidden in mental and cultural peculiarities of the person. In this sense, risk management should obviously include the analysis of peculiarities of this kind.

So, the risk management efficiency is basically determined by the possibility to reveal and estimate - more likely in terms of probability - negative possibilities included into a set of tools needed (intended for constructing) for implementing the required future. These possibilities included into the system of targets and tools are an implicit part of the required future model. As far as the model belongs to the future, which means that it is an image of something that does not exist, we deal with an imaginary object. The access to the object is possible by means of specific intellectual operations that let us construct a model basing on chosen targets proceeding from the available experience. This model will play a role of a regulative ideal heading further construction (engineering and technical) activities.

In this context, risk estimations have a range of features of an experimental procedure (to the extent that the risk analysis is based on experimental data and procedures of isolating causal links between desired and undesired possibilities in the set of needed constructive tools). However, it is basically conducted by means of theoretic modeling and imagining because it models (as yet) a subject that does not exist in the reality. The procedures of this kind, combining targets attributive for the experiment and demands for the results with ideal tools for implementation and imaginary objects instead of experimental ones, are known as "thought experiments". These procedures can claim center stage in being a tool and ground of risk management.

In modern methodology of social sciences, the thought experiment holds a valuable place. The reason is that, on the one hand, there are serious problems in experimental grounding of social models (because of high costs and/or unethicality of the major part of social experiments), on the other hand, there is a fundamental impossibility of classic (material) experiment grounding of forecasts and models of the future. In this case, it is critical to substitute the classic laboratory experiment by the thought experiment. If the last one could have the same functions and epistemic strength as the first does, the problem of grounds for forecasting and risk estimating will be solved. 
Both material and thought experiments do really have a range of common features. For example, U. Mäki argues that "The structure of experimentation, involving manipulation and isolation, is the same, while what is different is the way these controls and isolations are affected: by way of thinking and assuming and by way of material or causal manipulation", and "given this difference, it is not surprising that theoretical models are capable of effecting isolations more stringently than material models" [10, 306]. However, despite similarities, material and thought experiments are still different in terms of epistemic power, because "whereas experiments are versions of the real world captured within an artificial laboratory environment, models are artificial worlds built to represent the real world" [11,317].

The question about the significance of the difference between material and thought experiments, from the prognostic and evidential force point of view, is the key one for estimating the potential of risk analysis tools. Obviously, the trust to the thought experiment is based on the authority of the material experiment and experiment-empiric natural science that rests upon it. It is exactly natural science where the thought experiment (as a scientific method always used in conjunction with the material experiment) was born. The function of the thought experiment was either to conclude or to head experimental work. The conjunction, at the same time, is determined by the special features of the material experiment that the thought experiment does not have, which does not let us use the last one as an independent tool for analyzing the reality. There are two basic differences: 1) the material experiment operates the same substance it researches for - an electron in a particle accelerator is substantially, by material, does not differ from the same one in natural conditions: 2) conditions (premises) modeled in the material experiment are always realistic and they cannot go beyond empiric reality because of their physical availability. Unlike the material experiment, the thought one operates conceptual objects and it is limited in choosing model conditions by nothing but imagination capabilities. We can easily introduce counter-factual assumptions ("imagine, you have no body...") or involve transcendental objects ("let's admit aliens land on the Earth). So, by means of the thought experiment, it is impossible to figure out if a case modeled by it is real or it is a phantasm that cannot be actualized [12].

It is notable that if for classic sciences of reality, the isolated use of the thought experiment basically has no sense, in applied sciences of "future" - for instance in risk management - the situation is different. Because of the preponderance of constructive ground over ontological one, the thought experiment here is not just a tool for representation of actual reality and revealing its invariants (epistemic aim of the material experiment), but a tool for designing possible reality. And if, looking at the present, the possibilities' analysis is just a first step to discover the reality, then, looking ahead, the possibilities are the reality. And the thought experiment is able to organize and estimate these possibilities.

Consequently, when estimating risks by means of the thought experiment, we get a map reflecting some landscape possibilities' structure but not answering the question if this landscape exists instead of a mirror of the reality reflecting (in a possibly precise way) the world. And the map we have is not connected with this landscape (not yet existing) by relations of simple similarity. In real life, we have specific conditions and specific problems that exclude considered control of abstract possibilities: a bridge arm either stands or falls down but never both "possibilities" at the same time. In the case of forecasting, both possibilities exist to some extent. And a good map should take into consideration both branches of the future reflecting bunches of possibilities for each of optional trajectories. This map lets us choose an optimal route and switch if some reason makes us move from the chosen route and disturb the required future construction development. 


\section{Conclusion}

In social sciences, the thought experiment is a means for organizing subject fields and research tool setup. It is an organizational (in methodological meaning) but not research instrument, because the results obtained with the help of it cannot be qualified from the point of subject correlation (it is impossible to distinguish fantasy and reality by means of the thought experiment).

The thought experiment itself does not prove or deny anything. It just let us set up a problem and structure a subject area. However, when this tool is not essentially enough for sciences of actual reality, it absolutely matches applied forecast disciplines such as risk management, for instance, being not only a single option but powerful means.

The thought experiment constructs a map of our possibilities [12]. This map is not enough because, in reality, not all but some specific possibilities are implemented: in actual reality the real is primary to the possible (the second one proceeds from the first one, but not vice versa) and the question of a model probability is the question of ontology and it is not solved by means of the thought experiment (because it does not distinguish between the possibility and reality). However, when modeling future, the situation is drastically changed: there is no registered difference between abstract and implemented possibilities and a map of possibilities is not a reflection but plan regulating constructive efforts.

A high level of arbitrariness of the future that more and more depends on our material and technical practices lets us use the thought experiment as an effective tool of not just knowing (reflecting) but projecting, planning, whose important part is risk estimations. And the more the balance of ontological and constructive will shift to the last one, the more independent and necessary tool the thought experiment will become.

At the same time, it is hardly possible to substitute the ontological ground by the constructive one in full. And it means that however powerful engineering and technical means of the human being are, their plans will always be damaged by chains of causation, whose initial segments are much elder than human being history. Consequently, never so attractive would be to trust the future to the human mind, none the less, isolated use of the thought experiment and validity of possibility maps obtained by its means are of limited appliance. Hypothesis' messages still need to be tested for empiric veracity, which demands addressing to material experimental procedures. The future is still full of ambiguity and not any risk management can relieve us from the necessity of waiting for the fundamental anomaly - the "black swan" [13].

\section{References}

1. G. Holton, The Scientific Imagination: Case Studies (Cambridge, 1978)

2. D. North, Understanding the process of economic change (Princeton University Press, 2005)

3. N. Luhmann, Soziologie des Risikos (Walter de Gruyter, Berlin, NY, 1991)

4. U. Beck, From industrial society to the risk society, Theory, Culture and Society, v.9, no.1 (1992)

5. I. Frolov, A. Chusov, Forecast and reality, Moscow University Bulletin. Series 7. Philosophy, № 5 (2001)

6. V. Borkovskaya, W. Bardenwerper, and R. Roe, Interactive Teaching of Risk Management in the Russian Construction Industry, IOP Conf. Series: Materials Science and Engineering, 365 (2018)

7. V. Borkovskaya, W. Bardenwerper, and R. Roe, Sustainability Risk Management: The Case for Using Interactive Methodologies for Teaching, Training and Practice in 
Environmental Engineering and Other Fields. Advances in Economics, Business and Management Research (to be published)

8. M. Jones, Textbook on Torts, (London: Blackstone Press Ltd, 1996)

9. M. Kaverina, The Flooding of Zagorsk PSP Spoiled the Relations of Ingosstrakh and Munich Re, Vedomosti (2015)

10. U. Mäki, Models are experiments, experiments are models, Journal of Economic Methodology, vol. 12, issue 2 (2005)

11. Morgan M. Experiments versus models: New phenomena, inference and surprise, Journal of Economic Methodology vol. 12, issue 2 (2005)

12. O. Koshovets, T. Varkhotov, Experiments without concrete. The case of economics, Epistemology \& Philosophy of Science, vol. 49, no. 3 (2016)

13. N. Taleb, The black swan: the impact of the highly improbable, (Random House, 2007) 